\title{
Editorial, SWAT 2008 Special Issue
}

\author{
Joachim Gudmundsson
}

Received: 12 May 2009 / Accepted: 14 May 2009 / Published online: 20 May 2009

(C) Springer Science+Business Media, LLC 2009

This special issue contains a selection of seven papers from the 11th Scandinavian Workshop on Algorithm Theory (SWAT), which was held in Gothenburg, Sweden, on the 2nd to 4th of July, 2008. The first SWAT workshop was held in Halmstad, Sweden, in 1988. Since then it has been held biennially, rotating between the five Nordic countries-Denmark, Finland, Iceland, Norway and Sweden, with the exception of 2006 when it was in Riga. The conference program featured 36 presentations chosen from 111 submissions, covering a wide range of topics in algorithmic theory. This is reflected by the papers selected for the special issue whose topics range from persistent tries to metric clustering. The papers were invited based on their evaluation by the SWAT 2008 program committee, and went through the standard rigorous refereeing process of Algorithmica before being accepted to this special issue.

We wish to thank the authors for submitting their papers to the special issue, the referees for their thorough reviews and the journal for giving us the opportunity to compile this special issue. We hope that the readers will find the papers in it both interesting and enjoyable.

\section{Guest Editor}

J. Gudmundsson ( $\square)$

National ICT Australia Ltd, Sydney, Australia

e-mail: joachim.gudmundsson@nicta.com.au 